Jennifer C. Friberg, ILLINOIS STATE UNIVERSITY, jfribe@ilstu.edu Mandy Frake-Mistak, YORKUNIVERSITY,mfmistak@yorku.ca Ruth L. Healey, UNIVERSITYOFCHESTER, r.healey@chester.ac.uk Shannon Sipes, INDIANA UNIVERSITY, sipessm@indiana.edu JulieMooney, UNIVERSITYOFALBERTA, jmooney@ualberta.ca Stephanie Sanchez, UNIVERSITY OF NEWMEXICO, stephs@unm.edu Karena L.Waller, UNIVERSITY OF MELBOURNE, klwaller@unimelb.edu.au

\title{
A Developmental Framework for Mentorship in SoTL Illustrated by Three Examples of Unseen Opportunities for Mentoring
}

\section{ABSTRACT}

Mentoring relationships that form between scholars of teaching and learning occur formally and informally, across varied pathways and programs. In order to better understand such relationships, this paper proposes an adapted version of a three-stage model of mentoring, using three examples of unseen opportunities for mentoring in the Scholarship of Teaching and Learning (SoTL) to illustrate how this framework might be operationalized. We discuss how the adapted framework might be useful to SoTL scholars in the future to examine mentorship and how unseen opportunities for mentoring might shape how we consider this subset of mentorship going forward.

\section{KEYWORDS}

SoTL mentoring, mentoring framework, unseen mentoring, SoTL, faculty mentoring

\section{INTRODUCTION}

The Scholarship of Teaching and Learning (SoTL) as a field of inquiry has impact in multiple contexts, including through informal networks of peers, classrooms, and institutions (Frake-Mistak et al. 2020; Huber 2009). Mentorship has been used as an educational development tool within SoTL communities (Hubball, Clarke, and Poole 2010) to foster growth in SoTL theory, methodologies, and practice. Specifically, Hubball, Clarke, and Poole (2010) identified that SoTL mentors perform three critical, concrete practices: modeling SoTL productivity, facilitating SoTL research, and enabling SoTL networking. Such mentoring relationships benefit both participants: mentors develop as leaders in SoTL and mentees develop as SoTL researchers. While conventional mentorship relationships still prevail in SoTL, in which experienced faculty mentor early career faculty or new researchers, more recent literature emphasizes more dynamic mentorship roles, including students as partners $(\mathrm{SaP})$ and coresearchers (Healey, Flint, and Harrington 2014).

In this paper, we operationalize our interpretation of the relationship between SoTL and mentoring across varied mentoring pathways, and propose an adapted version of a three-stage model of 
mentoring (McKinsey 2016), using what we refer to as unseen opportunities for mentoring in SoTL to illustrate how this mentoring model might be used. These unseen opportunities may encompass formal or informal SoTL structures where possibilities exist for mentoring relationships to develop and move onward.

As an International Collaborative Writing Group (ICWG; Healey, Marquis, and Vajoczki 2013), our group consisted of faculty members, educational developers, and graduate students from Australia, Canada, the United Kingdom, and the United States. Though we have diverse disciplinary backgrounds, areas of research, and experiential levels in teaching and learning, each of us has engaged in SoTL work and we were intrigued by ways in which our adaptations of McKinsey's framework might be applied to consider mentorship in SoTL through a fresh lens.

Through our collaborative writing process, we utilized a team-based approach to writing and analysis (MacQueen et al. 2008; Saldaña 2016; Vander et al. 2017). During our face-to-face collaborations and analysis of both literature and personal experiences, we progressed through a variety of brainstorming activities before adapting McKinsey's mentorship framework and operationalizing it through three distinct examples of how mentoring can occur in unexpected ways.

It was important to each of us that we used examples of mentorship to describe and explain our adaptations to McKinsey's framework. While acknowledging that many examples of formal or informal mentorship structures could have been used to illustrate the stages of our adapted framework, we shared an interest in examining unseen opportunities for mentoring within formal SoTL structures that occurred within those and other contexts.

In our discussions, it was evident that unseen moments of mentoring had impacted each of us as SoTL scholars and we acknowledged that unanimously:

- Formal mentorship can be valuable but an individual's needs for support and development do not often fit into formalized structures. Rather, such support comes in small moments at unplanned times;

- As SoTL scholars, our own professional development in this field has emerged from 'unseen' opportunities to build reciprocal relationships that develop our understanding of and/or practice in SoTL further, perhaps pushing us to acquire new skills or think about familiar concepts in unfamiliar ways;

- SoTL represents a community of scholars rather than a narrowly focused discipline. The SoTL community is built organically at the level of interpersonal relationships. Unseen mentoring is one way in which this community grows; and

- By giving a name to mentoring relationships that emerge from unexpected sources or experiences, we can recognize them as legitimate and valuable forms of academic labor that result in advances to individual and community understanding of SoTL.

It is our hope that in exploring unseen opportunities for mentorship, they may become more expected and recognized explicitly in an effort to intentionally make space for them and cultivate another pathway towards quality mentoring in SoTL. With this in mind, we chose to apply our adapted framework to this type of mentorship to explore and better understand its characteristics.

In unpacking the characteristics of informal mentorship, we came to terms with and negotiated our respective understandings of SoTL. We aligned our definition of SoTL with Potter and Kustra $(2011,2)$ who describe SoTL as: 
The systematic study of teaching and learning, using established or validated criteria of scholarship, to understand how teaching (beliefs, behaviours, attitudes, and values) can maximize learning, and/or develop a more accurate understanding of learning, resulting in products that are publicly shared for critique and use by an appropriate community.

Furthermore, we agreed that mentoring is an integral part of SoTL and hence it is important to recognize how we engage in a variety of mentoring relationships in SoTL.

\section{MENTORING IN POSTSECONDARY EDUCATION}

Mentorship in academia exists in structurally distinct forms that may include formal and informal mentoring, peer or near-peer mentoring networks, or multi-mentor models. It is no different in the narrower field of SoTL. Formal mentoring programs are structured and deliberate, often organized around specific goals (Coles 2011). Formal mentoring allows greater participation among marginalized individuals such as women and people of color who may not have access to informal mentoring relationships (Beech et al. 2013; Boyd, Cintron, and Alexander-Snow 2010; Hansman 2002; Palepu et al. 1998; Ragins and Cotton 1991; 1999). However, further research has indicated that formal mentoring is limited by the initial development of the relationship because participants are compelled into the mentoring relationship through organizational assistance in which one or both participants may not share the same level of commitment in each other or motivations for entering into mentorship (Allen, Eby, and Lentz 2006; Eby and Lockwood 2005; Hansman 2003; Kram 1985).

In comparison, while informal mentoring lacks the structures seen in formal programs, these relationships begin as an organic process that relies upon connections made that are based on perceived shared values and similarities that promote the development of interdependence and fellowship (Ensher and Murphy 1997; Jones et al. 2018; Ragins and Cotton 1999). In such cases, mentoring relationships may be successful for mentees because those who participate as mentors choose to do so based on their personal investment in mentoring and in their partner and/or the psychosocial benefits that result from positive interpersonal connections (Ragins and Cotton 1999). These relationships are a type of "situated learning" that takes place in everyday experiences, thus building camaraderie and collegiality through everyday practice (Handley et al. 2006; Lave and Wenger). However, informal mentoring relationships are dependent upon mentees having access to a supportive network, which may be limited by organizational culture, gender, race/ethnicity, or class. Particularly for women and faculty of color, mentorship is an essential part of success and developing a sense of professional belonging within a discipline, department, and institution (Davidson and Foster-Johnson 2001; Davies and Healey 2019; Sorcinelli and Yun 2007).

\section{Mentoring pathways in SoTL: A framework}

In the academic literature we often find various forms of mentoring under the labels of students as partners, learning communities, advisors, critical friends, and so on (Cook-Sather, Bovill, and Felten 2014; Cox 2004; McKinsey 2016). This fluidity in mentorship structure recognizes no single approach to mentoring as superior, but instead notes that successful mentoring relationships are dynamic and that 
roles and functions of such relationships evolve to meet the needs, contexts, and stages of the individuals involved (Brandau, Studencnik, and Kopp-Sixt 2017; McKinsey 2016). At the same time, we recognize some broader similarities across mentoring pathways, particularly in formal mentoring relationships within existing programs or scaffolded systems (e.g. university arranged peer mentoring for new faculty members). These generally match mentors with mentees, provide timelines and guiding principles for establishing a mentoring relationship, and may even provide a structure for routine communications/exchanges between mentors and mentees.

Multiple pathways exist to quality mentoring experiences and these pathways may shift depending on needs, the context for mentoring, and/or desired outcomes of a mentoring relationship. Thus, there is no singular pathway to mentorship. At times, mentoring may occur within a developmental framework with both mentor and mentee receiving guidance and engaging in knowledge-sharing. In our overall conceptualization of mentoring, experience and structure are mutually beneficial, free from limiting power dynamics and immutable roles. In this sense, we suggest that mentoring can take place outside of "conventional" spaces and expectations that may no longer function well within the changing social organization of academia.

In seeking evidence of pathways toward mentoring, we reviewed literature focused on mentorship and, in doing so, found a three-stage model developed by McKinsey (2016) that describes the mentoring relationships that occur between faculty members and students across three distinct stages: mentoring in, mentoring through, and mentoring onward. This model follows a developmental process of bringing a newcomer to a topic or task, then scaffolding professional advancement accordingly. Thus, mentoring in represents a starting point, where newcomers get oriented to a task or topic. Mentoring through occurs through support provided to mentees as they develop advanced skills, abilities, and autonomy in their work. Logically, then, mentoring onward occurs through interactions that help students plan for life after graduation and/or entry into their selected professional contexts.

We immediately recognized that mentoring among SoTL scholars can be thought of in similar ways. As such, we suggest adaptations to McKinsey's framework to describe pathways for mentorship in SoTL that describe bringing a novice to a new topic or task, but in a manner that builds skills and efficacy amongst a broader group of stakeholders in the diverse field of SoTL. To that end, we envision adapting the stages of mentorship as follows:

1. mentoring in is directly analogous to McKinsey's definition in which novice SoTL scholars become oriented to the field via exposure to jargon, epistemologies, and cultural practices;

2. the second stage, mentoring through, offers scholars the opportunity to build selfefficacy in their knowledge and skills around SoTL and build scaffolded autonomy in their work; and

3. the third and final stage, mentoring onward, provides a pathway for an ongoing mentoring relationship, flexible in practice, that meets the professional developmental needs of both mentees and mentors.

It is important to note that in adapting McKinsey's framework, we made two important conceptual changes. First, we believe mentoring in SoTL is recursive rather than linear as McKinsey states. A mentee may be mentoring through in one context while at same time be mentoring in in another. For example, a SoTL scholar may be an expert in applying a discipline-specific pedagogy, but a novice in 
designing SoTL methodology to study its impact. Secondly, we removed any assumption of who the novice and expert SoTL scholars might be. We do not presume that SoTL mentors will always be faculty members and mentees always students or early career faculty. For example, at times, mentors may be relatively inexperienced students, new to SoTL, who offer perspectives and ideas to challenge expert SoTL scholars' thinking and/or processes. Table 1 presents a comparison of McKinsey's original mentorship framework with the adaptations we suggest to better align this mentorship pathway with SoTL practices.

Table 1. Adapting McKinsey's framework for SoTL mentorship

\begin{tabular}{|l|l|l|}
\hline MENTORING STAGE & $\begin{array}{l}\text { MCKINSEY'S ORIGINAL FRAMEWORK FOR } \\
\text { FACULTY-TO-STUDENT MENTORSHIP }\end{array}$ & $\begin{array}{l}\text { MCKINSEY'S ADAPTED FRAMEWORK FOR SOTL } \\
\text { MENTORSHIP }\end{array}$ \\
\hline Mentoring in & $\begin{array}{l}\text { A starting point for mentorship, where } \\
\text { faculty assist students in becoming } \\
\text { oriented to a task or topic }\end{array}$ & $\begin{array}{l}\text { Novice SoTL scholars become oriented } \\
\text { to the field via exposure to jargon, } \\
\text { epistemologies, and cultural practices }\end{array}$ \\
\hline Mentoring through & $\begin{array}{l}\text { Supports provided by faculty to } \\
\text { students as they develop advanced skills, } \\
\text { abilities, and autonomy in their work }\end{array}$ & $\begin{array}{l}\text { Offers scholars the opportunity to build } \\
\text { self-efficacy in their SoTL knowledge } \\
\text { and skills and build scaffolded } \\
\text { autonomy in SoTL through interactions } \\
\text { with experienced scholars who guide } \\
\text { aspects of that development }\end{array}$ \\
\hline Mentoring onward & $\begin{array}{l}\text { Interactions that help students plan for } \\
\text { life after graduation and/or entry into } \\
\text { their selected professional contexts }\end{array}$ & $\begin{array}{l}\text { Provides a pathway for an ongoing } \\
\text { mentoring relationship, flexible in } \\
\text { practice, that meets the professional } \\
\text { developmental needs of both mentees } \\
\text { and mentors }\end{array}$ \\
\hline
\end{tabular}

This framework for understanding how mentoring relationships develop provides a structure for examining formal and informal mentoring that occurs across academic spaces. Furthermore, it allows for stakeholders new to mentorship in fields such as SoTL to envision pathways towards forming relationships important to their own institutional or experiential positionality. For our group's purposes, the establishment of a framework for mentorship allowed the opportunity to explore the nature of unseen opportunities for mentoring relationships in a systematic manner.

\section{UNSEEN OPPORTUNITIES FOR MENTORING}

Our interest in unseen opportunities for mentoring developed from a series of conversations about mentorship in SoTL. We collectively realized that we were individually affected by various experiences with mentorship that emerged from unexpected and sometimes surprising encounters, within both formal and informal contexts. In the subsequent sections of this paper, we apply our adapted framework to three such examples of experiences with mentorship, highlighting unexpected instances when mentoring in, mentoring through, and mentoring onward transpired. These examples are 
grounded in our lived everyday experiences in an effort to provide a fulsome illustration of how mentoring relationships in SoTL can occur unexpectedly across stakeholders and contexts. We offer these examples for others to consider mentoring through a novel lens, reflect upon moments of unseen mentorship in their own contexts, and perhaps, watch for in the future.

We selected our exemplar cases carefully, with an eye toward illustrating situations that were often unrecognized as mentoring, where interactions with other SoTL scholars have changed our professional practice. Cases presented include the following: the peer review process within the International Journal for Students as Partners (IJSaP), the "critical friends" interactions interwoven in the International Society for the Scholarship of Teaching and Learning's (ISSOTL) ICWG face-to-face meeting structure, and scaffolds for supporting faculty new(er) to SoTL research. By identifying themes across our work, we hope to advance conceptualizations of mentoring in SoTL to inform and enhance existing and future SoTL structures.

\section{Mentoring in: International Journal of Students as Partners}

Supporting others to develop their writing for publication is a form of mentoring. However, the potential opportunity for mentoring as part of the formal processes of peer review in journal publications is sometimes unrecognized. This example makes unseen opportunities for mentoring in the formal structures of the process of a peer-reviewed journal explicit both in the identity of the reviewers and editors as mentors, and the reciprocal learning that editors and reviewers experience by reading the authors' work and each other's feedback. This example goes beyond the traditional editorreviewer-author relationships in which the editors and reviewers are senior/well-established professionals in the field.

The IJSaP was launched in 2016 to explore new perspectives, practices, and policies regarding how students, faculty, and professional staff work in partnership to enhance learning and teaching in higher education (International Journal for Students as Partners 2019). Henceforth the term 'staff is used to include faculty and professional staff. Adopting the ethos of student-staff partnership itself, the journal was designed around practicing student-staff partnerships within each structure of the journal:

1. the journal has six student-staff editorial teams from six different countries-Australia, Canada, Hong Kong, Malaysia, the United Kingdom, and the United States;

2. each submission is peer-reviewed by a reviewer who identifies as a student and a reviewer who identifies as a member of staff; and

3. the International Advisory Group of the journal is made up of an equal mixture of students and staff from across the world.

Authors (either students and/or staff) are invited to submit a range of different types of manuscripts (research articles, case studies, reflective essays, reviews, and opinion pieces).

Mentoring in, as described in our adaptation of McKinsey's framework, is the process wherein novice (in some way) SoTL scholars become oriented to the jargon, practices, and culture of SoTL. As a supportive developmental journal, IJSaP mentors in on a routine basis. Although the editors will not send a manuscript out for review if they feel it is likely to be rejected, they will provide developmental feedback prior to the review stage to allow the author(s) to develop the work and re-submit it prior to being sent to reviewers. In this way, the journal provides a starting point for newcomers either to writing or reviewing in the field of 'students as partners' to become oriented to the task and/or topic. Thus, a 
mentorship structure is embedded through reciprocal learnings between stakeholders in this editorial process as depicted in Figure 1.

Figure 1. The reciprocal learnings between stakeholders within the journal

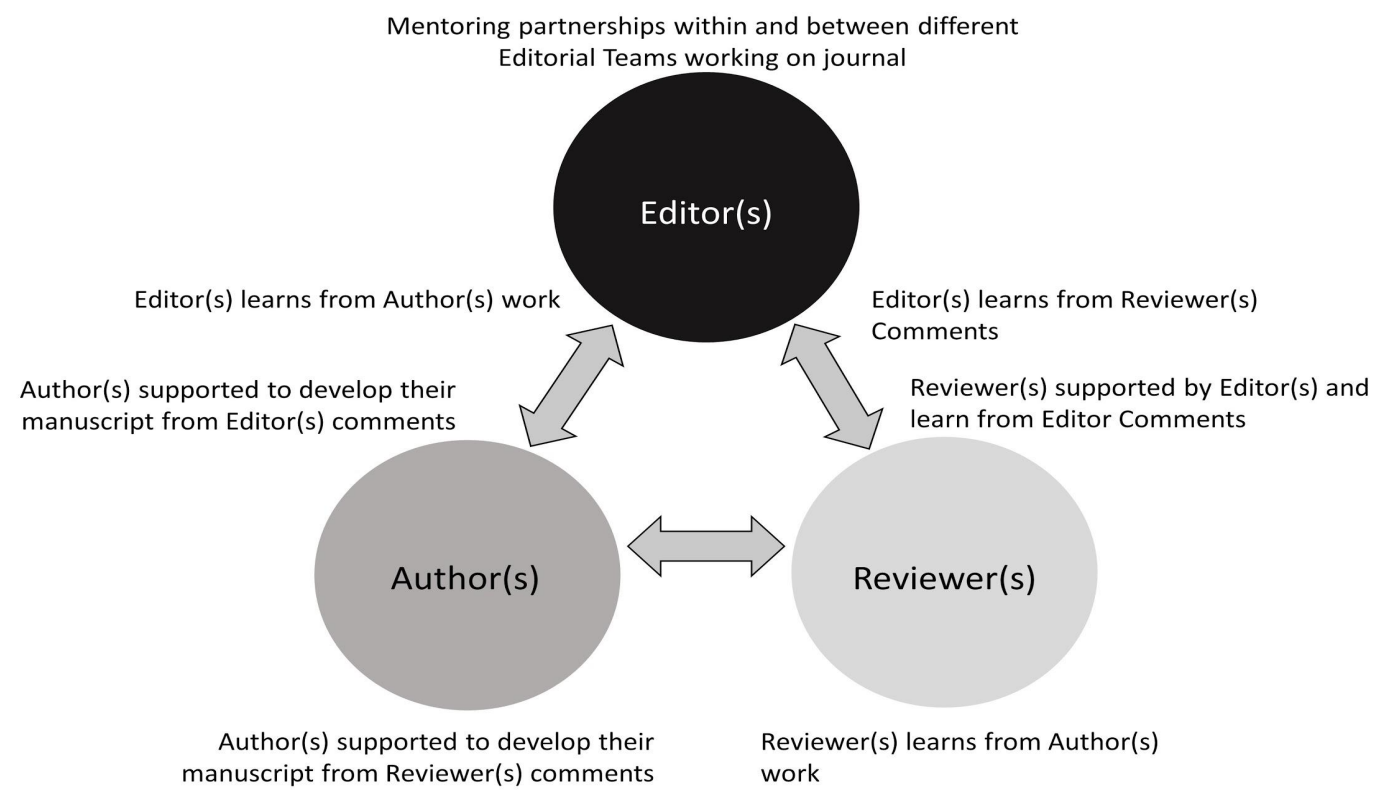

Unseen moments of mentoring in

Through a double-blind peer review process, IJSaP challenges conventional mentoring in expectations through unexpected, unseen mentor/mentee pairings as a part of their normal processes. The traditional roles of expert and novice are upended in each because the novice can take on any of the three roles (editor, reviewer, author). The unseen moments described below focus on the role of an author as both mentor and as mentee in two separate exemplars. Common to both is the notion that preconceptions about knowledge and expertise based on the role of the individual are removed from the peer review process.

\section{Author as Mentee}

As students and staff act as reviewers and editors to provide support to authors in developing their submitted manuscripts, individuals who self-identify as 'novice' in teaching and learning can be placed in the position of advisors to the author(s). These author(s) range from being experienced students or staff who have written and published extensively in the area to individuals who have not published at all or have not published SoTL research before. Therefore, a student reviewer and/or editor may be mentoring an individual who has significantly more experience than they have at writing for publication and/or the subject content. Thus, while the author as mentee pairing is expected, the notion that a reviewer or editor new to SoTL might mentor a more experienced author is less so. It provides an unseen opportunity for mentoring in, one that due to the double-blind nature of the peer review process might never be formally acknowledged. The student reviewer/editor, as a novice, learns about SoTL and publishing in working asynchronously with an author or group of authors. Interacting around the 
manuscript, then, becomes an unseen moment of mentorship. As the student develops a deeper and richer understanding of SoTL and the peer review process through exposure to scholarly work and processes inherent to publication, they develop the ability to provide constructive feedback as a reviewer, operating on a prescribed timeline to shepherd work forward.

\section{Author as Mentor}

Harder to envision, but perhaps even more unseen as a form of mentoring in, is the notion that an author experienced in doing and publishing SoTL work might act as a mentor to a more novice faculty/staff/student editor or reviewer. Reading the work of a more experienced other, learning about new ways of explaining SoTL, conducting SoTL, or discussing SoTL has the potential to be both influential to and supportive of the development of editors or reviewers as SoTL scholars. Authors also have the potential to mentor reviewers in how SoTL scholars respond to feedback, in a professional manner with clear communication and attention to reviewer commentaries. Thus, a secondary form of mentoring in is possible within this structure. We would challenge other journals that may not usually consider including students in their publication processes to attempt to do so. Expanding their scope to include and partner with students in this way explicitly offers a means of broadening dialogues within and about various disciplines.

\section{Mentoring through: International collaborative writing group "critical friends"}

ISSOTL has sponsored three iterations of International Collaborative Writing Groups

(ICWGs), which bring together scholars from around the globe to complete a shared SoTL project. ICWG groups complete their projects in three phases in a combination of remote (e.g., video/audio conference calling, email) and in-person collaborations. A broad overview of these phases is presented in table 2. Readers can refer to Healey, Marquis, and Vajoczki (2013) for additional information about the administration of the ICWG program, but note the following discussion of ICWG processes are specific to the 2019-2020 ICWG groups and thus may differ from prior iterations of ICWGs. While very similar in organization and implementation, our discussion of unseen mentorship below may not apply to previous iterations of the ICWG program if the critical friend's portion of the ICWG experience was designed or implemented differently.

In order to facilitate the entire ICWG process from start to publication, various stakeholders are involved, including:

- ICWG co-organizers who oversee the ICWG program on behalf of ISSOTL, selecting facilitators for the program and participants for each group topic;

- ICWG group facilitators who propose/develop topics for ICWGs and facilitate their group's work over the course of the ICWG program; and

- ICWG participants who are selected to be a part of the ICWG program and include faculty, staff and students interested in SoTL. 
Table 2. ICWG processes

\begin{tabular}{|l|l|l|}
\hline ICWG PHASE & OBJECTIVES & WHERE/WHEN WORK OCCURS \\
\hline Initial planning & $\begin{array}{l}\text { Co-organizers support group facilitators in working } \\
\text { with their topic groups to prepare initial summaries } \\
\text { of project plans and objectives. Initial critical friend } \\
\text { review of summaries by ICWG participants occurs. }\end{array}$ & $\begin{array}{l}\text { Work occurs remotely over a 4-5 } \\
\text { month period of time. }\end{array}$ \\
\hline $\begin{array}{l}\text { In-person } \\
\text { planning }\end{array}$ & $\begin{array}{l}\text { ICWGs work together to refine projects based on } \\
\text { critical friend inputs and iterative processes } \\
\text { stemming from ongoing discussions and feedback } \\
\text { sessions. These critical friend experiences occur in } \\
\text { various ways through the ICWG experience. }\end{array}$ & $\begin{array}{l}\text { Work occurs in person during a 2-3 } \\
\text { day workshop in advance of the } \\
\text { are some whole group sessions, but, } \\
\text { primarily, groups work separately. }\end{array}$ \\
\hline $\begin{array}{l}\text { Final } \\
\text { preparations }\end{array}$ & $\begin{array}{l}\text { Manuscripts are finalized and prepared for peer } \\
\text { review by co-organizers and Teaching and Learning } \\
\text { Inquiryreviewers with subsequent revision and } \\
\text { resubmission of the manuscript. }\end{array}$ & $\begin{array}{l}\text { Work occurs remotely over a 7-10 } \\
\text { month period of time. }\end{array}$ \\
\hline
\end{tabular}

Mentoring through, as described in our adaptation of McKinsey's framework, allows scholars the opportunity to build self-efficacy in their knowledge and skills around SoTL, and build scaffolded autonomy in their work. As a formal, collaborative experience, the ICWG program offers visible and evident forms of mentoring through. One example of this lies in the relationships built between group co-organizers and group facilitators. ICWG co-organizers are selected due to their experience with and familiarity around the ICWG process. Through regular communication and guidance to group facilitators regarding the logistics of group leadership, ICWG objectives, publishing timelines, and other aspects of the administration of the ICWGs, co-organizers mentor through by providing information group facilitators need to oversee their ICWG group's work and to serve as consultants to help address questions or overcome challenges in each group's work.

\section{Unseen moments of mentoring through}

While there were several opportunities for critical friend reviews as part of the ICWG process, we selected one that represents an unseen moment of mentoring through across SoTL experience and skill levels: critical friend summary reviews. These reviews are undertaken at the end of the Initial Planning phase, when ICWG participants are asked to critically review the 2,000-word summaries of two other ICWG topic groups. In the most recent iteration of the ICWGs, participants were asked to respond to the following questions in response to each summary:

1. What are the main strengths of the outline? 
2. How could the outline be even better? (e.g. What areas need further development? Were there any points of confusion as you read through the draft? What is missing? What could be left out?)

3. What other advice would you give the authors? (e.g. If the authors have included questions for which they would like feedback, what are your responses?)

4. Is there any other feedback that you would like to share?

ICWG Participants as Simultaneously Mentor and Mentee. Each participant was provided the following guidance: "your role is as a critical friend rather than a reviewer, so please give comments that will help the groups enhance the quality of their outlines rather than giving an evaluative judgement" (International Collaborative Writing Groups 2019, 1). Feedback was identifiable, not blinded, and was a required component of the program. Comments from critical friends were provided to each ICWG topic group in advance of the in-person planning phase and were used as one resource to refine ICWG writings and products.

As a result of critical friend reviews, each ICWG group received dozens of comments, inputs, and suggestions for improving their projects. During the in-person planning phase of the ICWG process, feedback was considered, trends in comments were noted, and adaptations to projects were made to improve and focus the work ahead. Because critical friend comments were not blinded, ICWG topic group members could seek out specific individuals during the in-person planning stage to engage in deeper discussion related to feedback provided. Questions could be addressed, comments could be clarified, and collegial relationships could be formed around a shared topic of engagement. Thus, this stage of the ICWG process provided a pathway towards mentoring through, for as critical friends assisted ICWG topic members in better understanding their topics and writing directions, they assisted in the construction of (group) self-efficacy and enhancement of knowledge around a given topic free from constraints of perceived expertise.

Initially, our group understood the critical friends process to be a routine aspect of the ICWG process, not understanding how influential it would be in our project's development. The mentoring through that occurred via the critical friend's process was an unseen opportunity that we reflect upon now with gratitude. ICWG participants represent a range of roles (student, faculty, staff), SoTL experiences (veteran, novice, in between), and social locations within their institutions (faculty, educational developer, graduate student). Despite these differences, each voice is given equal weight, as contributing perspectives of importance, as part of the critical friend process. Figure 2 provides an overview of the critical friend process. 
Figure 2. One example of a transition from formal, conventional mentorship to an unseen but reciprocal mentorship as part of ICWG processes

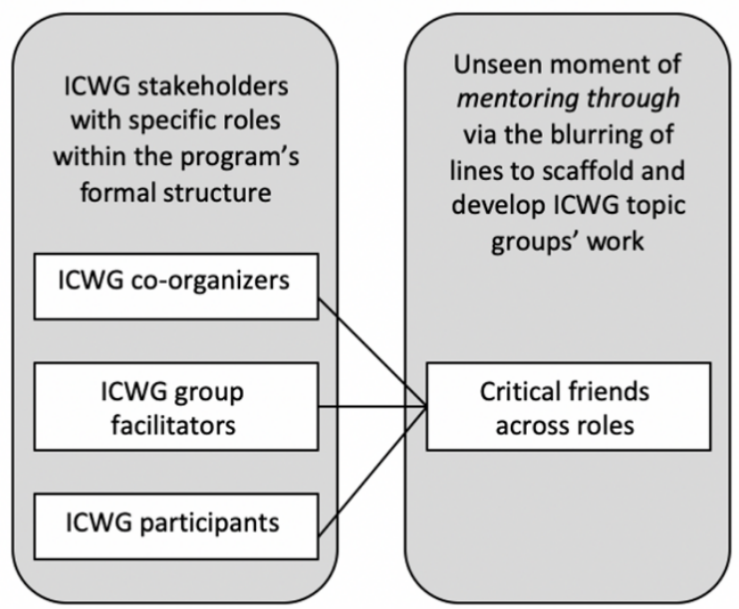

Each ICWG topic group was able to see what a diverse group of individuals perceived as strengths and weaknesses of their early works and make modifications and improvements to their manuscripts that reflected more than just input from a single group of stakeholders.

\section{Mentoring onward: An example from educational development}

Centres for teaching and learning (CTLs) at universities and colleges in Australia, Canada, the United Kingdom, and the United States (and elsewhere), provide a variety of pedagogically related support services for academic colleagues from across the disciplines. At many institutions support for SoTL research may include, but is not limited to, one-on-one consultations, courses, workshops, seminars, writing retreats, communities of practice, and conferences. The educational developer leading these professional development opportunities may find themselves filling a mentoring role to attendees as many are new(er) to SoTL as a field of inquiry, although they may be distinguished researchers within their discipline. The unseen moments described below focus on the role of an educational developer as both mentor and as mentee and explore how mentoring onward may occur across these roles.

Faculty members and graduate students with some form of teaching assistantship who wish to conduct research into their teaching practices or their students' learning may seek advice from educational developers. Of particular note, educational development or teaching and learning support may be restricted at some institutions meaning that only certain individuals (e.g. tenure, tenure-stream faculty) have access. Often this advice will take place early in the research process but may occur at any stage in the research process: design, implementation, analysis, or dissemination. Professional development spaces provide opportunities for collegial discussions to take place and mentoring relationships to develop between the SoTL researcher and educational developer. Moreover, these exchanges provide a pathway for an ongoing mentoring relationship that is both flexible in practice and meets the professional developmental needs of both mentees and mentors (see Figure 3 ). 
Figure 3. Knowledge exchange between SoTL scholar and educational developer facilitating knowledge exchange into mentoring onward

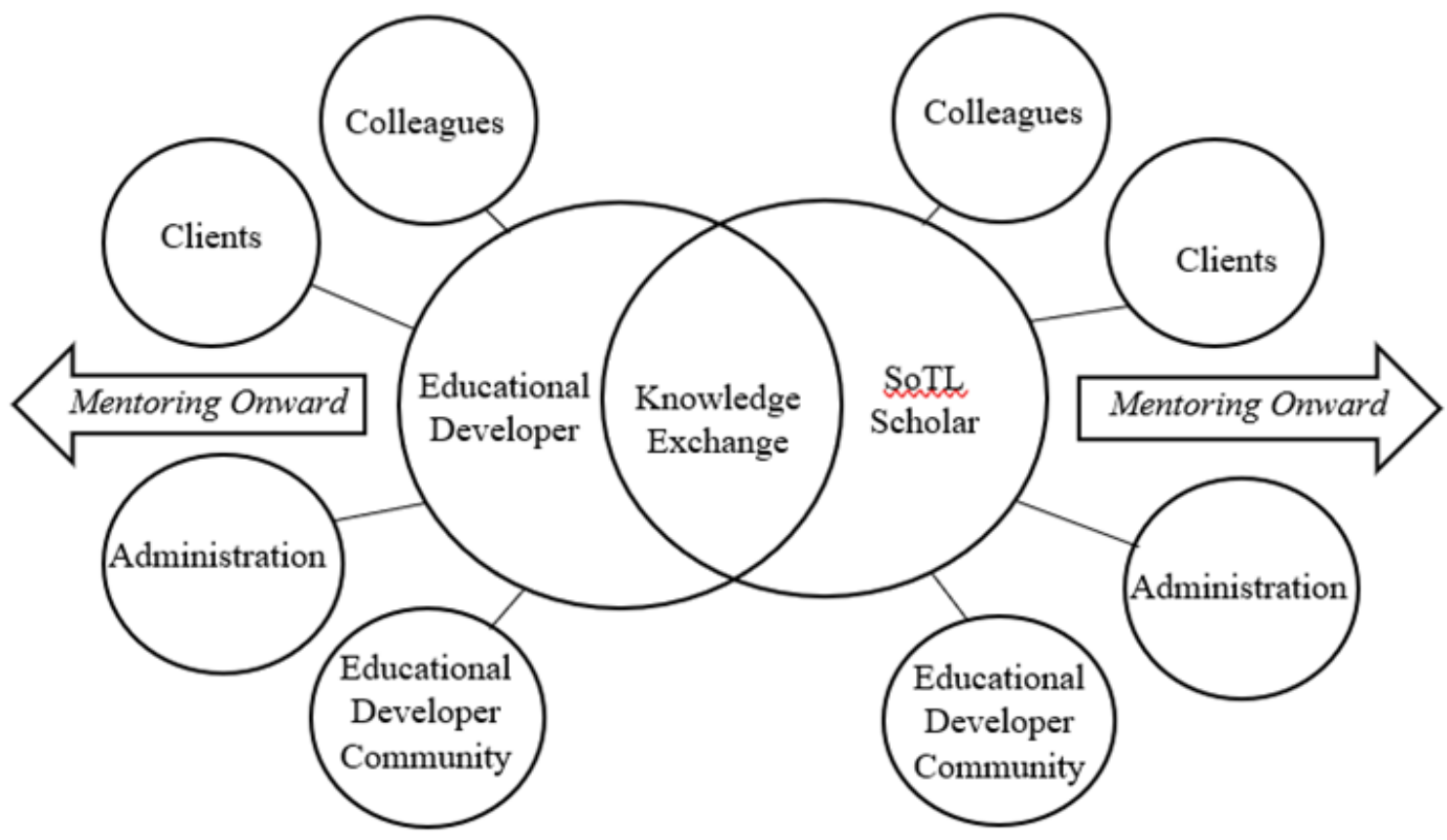

CTL programming often allows for open dialogue through questions, active learning strategies, problem solving, and/or curating and sharing of resources. It is not uncommon for collegial conversations to continue beyond the initial professional development opportunity, thus collegial conversations may transform into productive and professional relationships. Educational developers are hooked into opportunities that provide new and different ways of knowing, being, seeing, experiencing, and doing to those they support, as well as in their own learning by researching these new ways for faculty members and students. Through continued effort to engage in the consumption and doing of SoTL, developers aim to share their learning broadly through publications, presentations and workshops at conferences, institutional leadership within committees and action groups, and so on.

\section{Unseen moments of mentoring onward}

The unseen moments of mentoring in this example constitute reciprocal mentoring as the SoTL scholar, who may or may not be a novice researcher, begins to share disciplinary and methodological perspectives that may be unfamiliar to the educational developer, and the educational developer shares perspectives from SoTL or their own discipline. The novice SoTL scholar learns by conducting their own project and making it appropriately public. 


\section{Educational developer as mentor}

As educational developers provide pedagogical support and opportunities for professional development in teaching, faculty and graduate students may seek guidance in conducting SoTL research. At times, those seeking consultation may be experienced disciplinary researchers but novice SoTL scholars. At other times, those faculty or graduate students seeking assistance may have no formal research experience from which to draw. Thus, an educational developer may take on a mentoring role of someone who has significantly more content knowledge, but not necessarily an understanding of SoTL as a field of inquiry. These conversations provide the foundations for unseen opportunities in mentoring onward, due to the educational developer sharing process-based knowledge of doing SoTL research. The novice SoTL researcher engages in the process through the learning and conducting of their own project and, through "making appropriately public" (Felten 2013; Frake-Mistak et al. 2020), is able to disseminate and share outwardly lessons learned through being mentored by the educational developer.

\section{Educational developer as mentee}

The reciprocity experienced by the educational developer in this relationship may, perhaps, be even more invisible and thus unseen as a form of mentoring onward. Such mentoring onward situations may go unseen easily because the client-educational developer relationship may begin to resemble a collegial friendship, in which interactions occur so naturally and informally that they are viewed simply as social encounters to "catch up" on one another's latest projects. The latest projects may also become formal collaborations in which the formerly emerging SoTL scholar and the educational developer now see one another as peers in SoTL research. Furthermore, through these interactions, the educational developer is enabled to learn more about the disciplinary knowledge of the faculty or graduate student and can employ this knowledge in future workshops, consultations, courses, and so on with others, and within their own everyday work.

\section{DISCUSSION}

Those engaged in SoTL work represent a diverse field in all aspects of its practice: disciplinary knowledge and norms, methodological and theoretical orientations, social locations within an institution, cultural perspectives, and approaches to collaborative development as educators and researchers. Many come to engage in SoTL research through some form of mentorship; however, there is limited literature that focuses on how we engage in mentoring relationships within SoTL (Simmons and Marquis 2017). This work attempts to make a small dent in that gap by providing readers with a framework for exploring mentorship in SoTL and by highlighting unseen opportunities for SoTL mentoring. Both contributions offer new insights into what mentoring in SoTL might be and how it might be envisioned and planned for in the future.

\section{Applying the adapted framework}

Mentorship is both transformational and liminal in that it can impact one's academic and professional development and socialization dramatically. At the same time, it also requires participants to lean into ambiguity, be aware of what often might be unseen opportunities, and become, in turn, transitional learners or experts. Though our adapted version of McKinsey's framework for mentorship

Friberg, Jennifer C, Mandy Frake-Mistak, Ruth L. Healey, Shannon Sipes, Julie Mooney, Stephanie 
was explained through a single example of mentoring in SoTL within each of three stages, we envision that it could be used more broadly to better understand additional spaces in which mentoring might occur.

Very likely, mentoring in relationships are the most common in SoTL. They represent the practice of bringing new stakeholders to SoTL and would encompass experiences such as "intro to SoTL" learning communities, experts' recruitment of a novice partner in planning SoTL projects, or the sharing of SoTL work with colleagues unaware of that body of literature. Mentoring in, as the gateway to SoTL, is an important form of advocacy for the field, and seems well represented in our perceptions, across SoTL experiences, programs, and efforts. This is not to suggest that mentoring through or mentoring onward are not as important, as these add nuance and complexity to the enterprise of SoTL. When mentoring relationships end at the mentoring in stage, mentees are not able to move through and onward to spaces of increased SoTL self-efficacy and confidence as SoTL scholars. Thus, it occurred to us as we reflected on our adaptation of McKinsey's framework to SoTL that it could represent mentoring as a comprehensive framework, one that envisions pathways towards mentoring across different levels of SoTL experience to build a broad and diverse community of SoTL scholars. Through collegial conversations and professional development opportunities as illustrated in the above exemplars, mentoring work supports people who would not, and at times cannot, engage in SoTL otherwise. By engaging in what Roxå and Mårtensson (2009) call “sincere conversations” (p. 554), beyond their immediate and siloed contexts, faculty may be contributing in a shift to teaching and learning cultures, although seemingly subtle. Roxå and Mårtensson advocate that most educators are likely to rely on small groups, or significant networks, where collegial conversations support engagement in action research and contributions to SoTL literature. We posit that this is reciprocal mentorship in that both parties are mutually benefiting as a result of the process.

As mentoring onward spirals out, networks and communities of SoTL scholars develop. For example, CTL clients who have participated in a professional development opportunity continue along the mentorship framework. In doing so, they propel mentorship onward as they present at conferences, engage in meaningful discussions in increasingly broad contexts, publish their SoTL projects, or serve as invited speakers and panelists about SoTL. In this way, their work extends the framework onward even further. Also, important to note is that while mentoring in, mentoring through, and mentoring onward may occur between two individuals over a sustained period of time, it could also occur in a much less systematic manner, as mentor-mentee networks emerge organically from relationships that develop across contexts.

\section{Further examination of unseen opportunities for mentorship}

Unseen opportunities in SoTL represent spaces that are unarticulated, perhaps unexpected, and may result from a blending of roles or a blurring of lines between distinct roles within formal and informal mentoring structures. Our exemplar case studies suggest that unseen opportunities for mentorship occur when conventional spaces and expectations are upended in critical ways, such as:

1. When a traditional mentoring hierarchy is deconstructed to engage "novice" SoTL scholars in offering critical feedback to "expert" SoTL scholars. Through this process, preconceptions of who can produce knowledge and who can possess expertise are 
significantly altered, as was illustrated by the mentoring in process of IJSaP in which student and staff pairs offer advice through a double-blind process;

2. When mentorship occurs across a variety of SoTL experiences and skill levels to provide developmental support to advance individual development through engagement across multiple experts and multiple learners. This was depicted in the mentoring through of ICWG critical friends experience, wherein individuals moved between being experts and learners as groups engaged in a co-constructed interdisciplinary feedback loop; and

3. When mentoring is an ongoing reciprocal process in which the roles of mentor and mentee are less defined. As identified in the mentoring onward experience of faculty development, reciprocal mentorship occurs if and when expertise associated with rank/status (faculty or instructor) and title (educational developer) is set aside to learn and develop within SoTL work generally or within discipline-specific, contextual approaches to SoTL.

Across each phase examined in our case studies we suggest that context is of utmost significance to the emergence of previously unseen mentoring opportunities. The positionalities and roles of individuals involved, as well as expectations of processes and intended outcomes within professional and educational settings, interact to influence how mentoring unfolds and what mentoring looks like in specific moments. In this sense, mentoring is co-constructed and situational, with context establishing numerous pathways to mentor or to be mentored. Within the existing literature, there is agreement that mentoring both as a process and relationship is influenced by context (Blake-Beard, Murrell, and Thomas 2007; Fletcher and Mullen 2012; Giscombe 2007; Kochan 2002). Thus, we feel strongly that awareness of unseen opportunities for mentorship can help people to recognize them, seek out ways to take advantage of them, and appreciate the contributions such opportunities make to the broader field of SoTL, all in an effort to ensure that the lack of visibility of these opportunities does not act as a hinderance to the mentorship we seek to promote.

\section{Future directions and conclusion}

We started this work thinking collectively about what the practice of mentorship in SoTL looks like. As we continued through our work together, we moved from reflecting on the practice of mentorship to the when and how of mentorship across SoTL practices. We believe this is a worthwhile area to study, going forward, and submit that our adaptations to McKinsey's mentorship framework allow for a developmental (but not uni-directional) view of mentorship that can be used by others to better understand the impacts of mentorship experiences across contexts and stakeholders. Additionally, the adapted framework can be referenced as a scaffold for the development of mentoring programs that bridge the span from novice to expert, allowing scholars to realize the full potential of their SoTL work.

Based on the cases we presented in this paper, it would seem that unseen opportunities for mentorship appear to have value for novice, emerging, and veteran scholars. With this knowledge, the challenge becomes making the unseen visible so that these unarticulated moments of mentoring become more recognized and routine. Accomplishing this necessitates the identification of places and times where unseen opportunities for mentorship exist, purposefully and systematically identifying ways in which these moments present themselves and planning for their occurrence so that they might more frequently be taken advantage of.

Friberg, Jennifer C, Mandy Frake-Mistak, Ruth L. Healey, Shannon Sipes, Julie Mooney, Stephanie 
Although outside the scope of this paper, a notable consideration in light of increased awareness and concern for educational equity and institutionalized oppression is that "mentoring is often a racialized and gendered practice that needs to be thoughtfully configured to meet the needs of diverse faculty" (Zambrana et al. 2015, 68). While this paper did not explore or interrogate race, ethnicity, or gender, the literature supports "identify-informed mentoring" to "recognize, validate, and nurture" the "perspectives and experiences" of underrepresented minority faculty as assets to their work, departments, and institutions (Hsieh and Nguyen 2020, 169). Such identity informed mentoring directly addresses unique challenges associated with "marginalization, overt and covert racism, and a disproportionate share of activities that do not advance careers" (Beech et al. 2013, 2). The need for identity based mentoring emphasizes the critique that traditional configurations of mentoring are not always accessible or meaningful across diverse groups but can be understood as acts of resistance to educational institutions and systems that are not designed for all to succeed. Similar to identity-based mentoring, our conceptualization of unseen mentoring falls within a continuum of mentoring relationships that call for a reframing and re-examination of how, when, and with whom mentoring occurs and what inclusive mentoring demands.

Members of the SoTL community seek ways to share their learning with other SoTL scholars within the community, as well as with the broader teaching and learning community across postsecondary education. Stemming from our work in this paper is our recognition that there is a need to mentor people in SoTL, particularly for those who may be going through unfamiliar practices or processes in a field of study that is new in some way-with their peer-group, administration and management, ethical review boards, institutional discourses, institutional policies, and so on. Advocacy work in all aspects of SoTL is essential. Mentorship allows a space for this work to occur. A core element of advocacy is to make what is invisible, visible by helping those who engage in SoTL recognize that their research is valuable, important, and critical to the development and learning of their students and colleagues. Through a developmental mentoring approach, whether mentoring in, through, or onward, it is possible to hook faculty, graduate students, educational developers, and others into SoTL and engage them in this field of inquiry.

Jennifer Friberg is the Interim Director for the Center for Teaching, Learning, \& Technology, the Cross Endowed Chair in the Scholarship of Teaching and Learning, and a Professor of Communication Sciences and Disorders at Illinois State University (USA). She is the founding Associate Editor for Teaching and Learning in Communication Sciences \& Disorders and is a member of ISSOTL's Advocacy Committee.

Mandy Frake-Mistak, PhD, is an educational developer at the Teaching Commons, York University, Ontario (CAN). She is an active SoTL researcher and Fellow of the International Society for the Scholarship of Teaching and Learning. She is secretary of the Educational Developers Caucus, and the Chair of the Accreditation Committee of the Educational Developer Caucus.

Ruth L. Healey is an Associate Professor in Pedagogy in Higher Education at the University of Chester, UK. She is a National Teaching Fellow and a Fellow of the International Society for the Scholarship of Teaching and Learning.

Shannon M. Sipes is Director of the Scholarship of Teaching \& Learning Program and a Lead Instructional Consultant in the Center for Innovative Teaching and Learning at Indiana University (USA). She is a member of ISSOTL's Advocacy Committee as well as the Convenings Committee. 
Julie A. Mooney is a PhD candidate specializing in Educational Policy Studies at the University of Alberta (CAN), with a background in Educational Development. She is a 3M National Teaching Fellow and a Social Sciences \& Humanities Research Council (SSHRC) Doctoral Fellow.

Stephanie M. Sanchez is the Associate Director of student learning at the Center for Teaching and Learning and lecturer in Chicana/o Studies at the University of New Mexico (USA).

Karena L. Waller is an Associate Professor (in Microbiology and Immunology, and Higher Education) and Deputy Program Director of the Bachelor of Biomedicine at The University of Melbourne (AUS). She is also an ISSOTL Regional Vice-President (Asia-Pacific) and member of the Recognition Committee.

\section{REFERENCES}

Allen, Tammy D., Lillian T. Eby, and Elizabeth Lentz. 2006. “Mentorship Behaviors and Mentorship Quality Associated with Formal Mentoring Programs: Closing the Gap between Research and Practice." Journal of Applied Psychology91, no. 3: 567-78. https://doi.org/10.1037/0021-9010.91.3.567.

Beech, Bettina M., Jorge Calles-Escandon, Kristen G. Hairston, Sarah E. Langdon, Brenda A. Latham-Sadler, and Ronny A. Bell. 2013. "Mentoring Programs for Underrepresented Minority Faculty in Academic Medical Centers: A Systematic Review of the Literature." Academic Medicine 88, no. 4: 541-49. https://doi.org/10.1097/acm.0b013e31828589e3.

Blake-Beard, Stacey D., Audrey Murrell, and David Thomas. 2007. "Unfinished Business: The Impact of Race on Understanding Mentoring Relationships." In The Handbook of Mentoring at Work: Theory, Research, and Practice, edited by Belle R. Ragins and Kathy E. Kram, 223-47.

Boyd, Tammy, Rosa Cintron, Mia Alexander-Snow. 2010. "The Experience of Being a Junior Minority Female Faculty Member." Forum on Public Policy Online 2010, no. 2.

Brandau, Johannes, Peter Studencnik, and Silvia Kopp-Sixt. 2017. "Dimensions and Levels of Mentoring: Empirical Findings of the First German Inventory and Implications for Future Practice." Global Education Review4, no. 4: 5-19. https://ger.mercy.edu/index.php/ger/article/view/288.

Coles, Ann. 2011. "The Role of Mentoring in College Access and Success. Research to Practice Brief." Institute for Higher Education Policy. Retrieved from https://eric.ed.gov/?id=ED520415.

Cook-Sather, Alison, Catherine Bovill, and Peter Felten. 2014. Engaging Students as Partners in Learning and Teaching: A Guide for Faculty. San Francisco: Jossey-Bass.

Cox, Milton D. 2004. "Introduction to Faculty Learning Communities." New Directions for Teaching and Learning 2004, no. 97: 5-23. https://doi.org/10.1002/tl.129.

Davidson, Martin N., and Lynn Foster-Johnson. 2001. "Mentoring in the Preparation of Graduate Researchers of Color." Review of Educational Research 71, no. 4: 549-74. https://doi.org/10.3102/00346543071004549.

Davies, Chantal, and Ruth L. Healey. 2019. "Hacking Through the Gordian Knot: Can Facilitating Operational Mentoring Untangle the Gender Research Productivity Puzzle in HE?" Studies in Higher Education 44, no. 1: 31-44. https://doi.org/10.1080/03075079.2017.1333494.

Eby, Lillian T., and Angie Lockwood. 2005. "Protégés and Mentors' Reactions to Participating in Formal Mentoring Programs: A Qualitative Investigation." Journal of Vocational Behavior67, no. 3: 441-58. https://doi.org/10.1016/j.jvb.2004.08.002.

Ensher, Ellen A., and Susan E. Murphy. 1997. "Effects of Race, Gender, Perceived Similarity, and Contact on Mentor Relationships." Journal of Vocational Behavior 50, no. 3: 460-81. https://doi.org/10.1006/jvbe.1996.1547.

Felten, Peter. 2013. "Principles of Good Practice in SoTL." Teaching and Learning Inquiry 1, no. 1: 121-25. https://doi.org/10.2979/teachlearninqu.1.1.121.

Fletcher, Sarah J. and Carol A. Mullen. 2012. The SAGE Handbook of Mentoring in Education. London, UK: SAGE. 
Frake-Mistak, Mandy, Heidi L. Marsh, Geneviève Maheux-Pelletier, and Siobhan Williams. 2020. “Making SoTL Stick: Using a Community-Based Approach to Engage Faculty in the Scholarship of Teaching and Learning." In Evidence-Based Faculty Development Through the Scholarship of Teaching and Learning, edited by Michelle L. Amos and Rachel C. Plews. IGI Global: Hershey, PA.

Giscombe, Katherine. 2007. "Advancing Women through the Glass Ceiling with Formal Mentoring." In The Handbook of Mentoring at Work: Theory, Research, and Practice, edited by Belle R. Ragins and Kathy E. Kram, 549-71.

Handley, Karen, Andrew Sturdy, Robin Fincham, and Timothy Clark. 2006. "Within and Beyond Communities of Practice: Making Sense of Learning through Participation, Identity and Practice." Journal of Management Studies 43, no. 3: 641-53. https://doi.org/10.1111/j.1467-6486.2006.00605.x.

Hansman, Catherine A., ed. 2002. Critical Perspectives on Mentoring: Trends and Issues. ERIC Clearinghouse on Adult, Career, and Vocational Education, Center on Education and Training for Employment, College of Education, the Ohio State University.

Hansman, Catherine A. 2003. "Reluctant Mentors and Resistant Protégés: Welcome to the 'Real' World of Mentoring." Adult Learning 14, no. 1: 14-16. https://doi.org/10.1177\%2F104515950301400103.

Healey, Mick, Abbi Flint, and Kathy Harrington. 2014. Engagement Through Partnership: Students as Partners in Learning and Teaching in Higher Education. York, UK: Higher Education Academy.

Healey, Mick, Beth Marquis, and Susan Vajoczki. 2013. "Exploring SoTL Through International Collaborative Writing Groups." Teaching and Learning Inquiry 1, no. 2: 3-8. https://doi.org/10.20343/teachlearninqu.1.2.3.

Hsieh, Bettina, and Huong Tran Nguyen Huong. 2020. "Coalitional Resistance: Challenging Racialized and Gendered Oppression in Teacher Education." Journal of Teacher Education. https://doi.org/10.1177\%2F0022487120960371.

Hubball, Harry, Anthony Clarke, and Gary Poole. 2010. "Ten-Year Reflections on Mentoring SoTL Research in a Research-Intensive University." International Journal for Academic Development 15, no. 2: 117-29. https://doi.org/10.1080/13601441003737758.

Huber, Mary T. 2009. "Teaching Travels: Reflections on the Social Life of Classroom Inquiry and Innovation." International Journal for the Scholarship of Teaching and Learning 3, no. 2: Article 2. https://doi.org/10.20429/ijsotl.2009.030202.

International Collaborative Writing Group. 2019. [Email Communication].

International Journal for Students as Partners 2019. "Vision." International Journal for Students as Partners. https://mulpress.mcmaster.ca/ijsap/. [accessed 7th October 2019].

Jones, Heather A., Paul B. Perrin, Mary B. Heller, Selamawit Hailu, and Christina Barnett. 2018. "Black Psychology Graduate Students' Lives Matter: Using Informal Mentoring to Create an Inclusive Climate Amidst National Race-Related Events." Professional Psychology: Research and Practice 49, no. 1: 75-82. https://doi.org/10.1037/pro0000169.

Kochan, Frances K., ed. 2002. The Organizational and Human Dimensions of Successful Mentoring Programs and Relationships. IAP.

Kram, Kathy E. 1985. Mentoring at Work: Developmental Relationships in Organizational Life. University Press of America.

Lave, Jean, and Etienne Wenger. 1991. Situated Learning: Legitimate Peripheral Participation. Cambridge: Cambridge University Press.

MacQueen, Kathleen, Eleanor McLellan-Lemal, Kelly Bartholow, and Bobby Milstein. 2008. “Team-Based Codebook Development: Structure, Process, and Agreement. In Handbook for Team-Based Qualitative Research, edited by Greg Guest and Kathleen M. MacQueen, 119-36. AltaMira Press.

McKinsey, Elizabeth. 2016. “Faculty Mentoring Undergraduates: The Nature, Development, and Benefits of Mentoring Relationships." Teaching \& Learning Inquiry4, no. 1:25-39. https://doi.org/10.20343/teachlearninqu.4.1.5.

Palepu, Anita, Robert H. Friedman, Rosalind C. Barnett, Phyllis L. Carr, Arlene S. Ash, Laura Szalacha, and Mark A. Moskowitz. 1998. "Junior Faculty Members' Mentoring Relationships and Their Professional 
Development in US Medical Schools." Academic Medicine: Journal of the Association of American Medical Colleges 73, no. 3: 318-23. https://doi.org/10.1097/00001888-199803000-00021.

Potter, Michael. K., and Erika D. H. Kustra. 2011. "The Relationship between Scholarly Teaching and SoTL: Models, Distinctions and Clarifications." International Journal for the Scholarship of Teaching and Learning 5, no. 1. https://digitalcommons.georgiasouthern.edu/ij-sotl/vol5/iss1/23/

Ragins, Belle R., and John L. Cotton. 1991. "Easier Said than Done: Gender Differences in Perceived Barriers to Gaining a Mentor." Academy of Management Journa/34, no. 4: 939-51. https://doi.org/10.5465/256398.

Ragins, Belle R., and John L. Cotton. 1999. "Mentor Functions and Outcomes: A Comparison of Men and Women in Formal and Informal Mentoring Relationships." Journal of Applied Psychology, 84, no.4: 529-50. https://doi.org/10.1037/0021-9010.84.4.529.

Roxå, Torgny, and Katarina Mårtensson. 2009. "Significant Conversations and Significant Networks-Exploring the Backstage of the Teaching Arena." Studies in Higher Education 34, no. 5: 547-59. https://doi.org/10.1080/03075070802597200.

Saldaña, Johnny. 2016. The Coding Manual for Qualitative Researchers. 3rd ed. Thousand Oaks, CA: Sage.

Simmons, Nicola, and Elizabeth Marquis. 2017. "Promoting and Celebrating International SoTL Collaborations: An Introduction to the Special Issue." The Canadian Journal for the Scholarship of Teaching and Learning 8, no: 2. https://doi.org/10.5206/cjsotl-rcacea.2017.2.1.

Sorcinelli, Mary D., and Jung Yun. 2007. "From Mentor to Mentoring Networks: Mentoring in the New Academy." Change: The Magazine of Higher Learning 39, no. 6: 58-61. https://doi.org/10.3200/CHNG.39.6.58-C4.

Vander Kloet, Marie, Mandy Frake-Mistak, Michelle K. McGinn, Marion Caldecott, Erin D. Aspenlieder, Jacqueline L. Beres, Sherry Fukuzawa, Alice Cassidy, and Apryl Gill. 2017. "Conditions for Contingent Instructors Engaged in the Scholarship of Teaching and Learning." The Canadian Journal for the Scholarship of Teaching and Learning 8, no. 2: Article 9. https://doi.org/10.5206/cjsotl-rcacea.2017.2.9.

Zambrana, Ruth E., Rashawn Ray, Michelle M. Espino, Corinne Castro, Beth D. Cohen, and Jennifer Eliason. 2015. "'Don't Leave Us Behind': The Importance of Mentoring for Underrepresented Minority Faculty." American Educational Research Journa/52, no. 1: 40-72. https://doi.org/10.3102/0002831214563063.

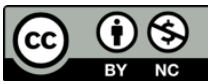

Copyright for the content of articles published in Teaching \& Learning Inquiry resides with the authors, and copyright for the publication layout resides with the journal. These copyright holders have agreed that this article should be available on open access under a Creative Commons Attribution License 4.0 International (https://creativecommons.org/licenses/by-nc/4.0/). The only constraint on reproduction and distribution, and the only role for copyright in this domain, should be to give authors control over the integrity of their work and the right to be properly acknowledged and cited, and to cite Teaching \& Learning Inquiryas the original place of publication. Readers are free to share these materials - as long as appropriate credit is given, a link to the license is provided, and any changes are indicated. 


\section{University Library}

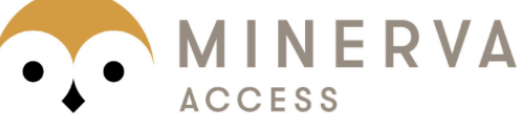

A gateway to Melbourne's research publications

Minerva Access is the Institutional Repository of The University of Melbourne

Author/s:

Friberg, JC;Frake-Mistak, M;Healey, R;Sipes, S;Mooney, J;Sanchez, S;Waller, K

Title:

A Developmental Framework for Mentorship in SoTL Illustrated by Three Examples of Unseen Opportunities for Mentoring

Date:

2021

Citation:

Friberg, J. C., Frake-Mistak, M., Healey, R., Sipes, S., Mooney, J., Sanchez, S. \& Waller, K. (2021). A Developmental Framework for Mentorship in SoTL Illustrated by Three Examples of Unseen Opportunities for Mentoring. Teaching \& Learning Inquiry, 9 (1), pp.395-413. https://doi.org/10.20343/teachlearninqu.9.1.26.

Persistent Link:

http://hdl.handle.net/11343/267835

License:

CC BY-NC 